\title{
SISTEMA MULTIPORTAS DE JUSTIÇA E A ATUAÇÃO DO PROJETO DE EXTENSÃO CONFLITOS SOCIAIS E DIREITOS HUMANOS
}

http://dx.doi.org/10.21527/2176-6622.2020.53.168-181

Recebido em: 21/8/2019

Modificações solicitadas em: 13/11/2019

Aceito em: 26/2/2020

Jaqueline Beatriz Griebler

Mestranda do Programa de Pós-Graduação em Direito - Mestrado em Direitos Humanos da Universidade Regional do Noroeste do Estado do Rio Grande do Sul - Unijuí. Bacharel em Direito pela Unijuí. Integrante do Grupo de pesquisa Biopolítica e Direitos Humanos (CNPq). http://lattes.cnpq.br/4906898654916920. https://orcid.org/0000-0003-0326-3482. jaqeline-beatriz@hotmail.com

Fernanda Serrer

Doutoranda em Educação no Programa de Pós-Graduação Stricto Sensu Educação nas Ciências da Universidade Regional do Noroeste do Estado do Rio Grande do Sul (Unijuí), RS, Brasil. Professora do curso de Direito da Unijuí. Extensionista no Projeto de Extensão "Conflitos Sociais e Direitos Humanos: alternativas adequadas de tratamento e resolução". http://lattes.cnpq.br/4832388326172885. https://orcid. org/0000-0002-7882-5075. fernanda.serrer@unijui.edu.br.

\section{RESUMO}

O presente trabalho faz uma análise do Sistema Multiportas de Justiça e a atuação do Projeto de Extensão "Conflitos Sociais e Direitos Humanos" do curso de Direito da Unijuí, tendo como questão central quais são os limites e possibilidades de um Sistema Multiportas de Justiça no contexto jurisdicional brasileiro, bem como se o projeto de extensão "Conflitos Sociais e Direitos Humanos" pode ser considerado uma experiência em busca de um Sistema Multiportas de Justiça. O objetivo geral deste estudo é compreender as várias "portas" de resolução de conflitos disponíveis no e em paralelo com o poder Judiciário. Inicialmente, estuda o conflito, percebendo suas diferentes concepções, sejam positivas ou negativas, e as consequências decorrentes das diversas formas de compreensão dos conflitos intersubjetivos. Após, passa a analisar a crise atual do poder Judiciário e o Sistema Multiportas como uma possível alternativa à crise. Por fim, expõe o trabalho realizado pelo Projeto de Extensão Universitária "Conflitos Sociais e Direitos Humanos" da Unijuí, como uma forma de aplicação do Sistema Multiportas de Justiça. Finaliza concluindo que o Sistema Multiportas de Justiça pode ser uma ferramenta eficaz para atender aos interesses dos sujeitos em conflito a partir da inauguração de novos modos de conceber os conflitos intersubjetivos, apresentando as atividades do Projeto de Extensão Universitária como vivências de um Sistema Multiportas de Justiça.

Palavras-Chave: Sistema multiportas. Justiça. Conflitos. Extensão universitária.

\section{MULTIPORTPORT JUSTICE SYSTEM AND THE PERFORMANCE OF THE} EXTENSION PROJECT OF SOCIAL CONFLICTS AND HUMAN RIGHTS

\section{ABSTRACT}

The present study analyzes the Multiport Justice System and the performance of the Extension Project "Social Conflicts and Human Rights" of Unijuí's Law Course, focusing on the limits and possibilities of a Multiport Justice System in the context of Brazilian jurisdiction as well as whether the extension project "Social Conflicts and Human Rights" can be considered an experience in search of a Multiport Justice System. The general objective of this study is to understand the high number of quot; gates quot; of conflict resolution available in and in line with the judiciary. Initially, it studies the conflict, perceiving its different conceptions, whether positive or negative and the consequences arising from the several ways of understanding intersubjective conflicts. Furthermore, it analyzes the current crisis of the judiciary and the multiport system as a possible alternative to the crisis. Finally, it exposes the work done by Unijuí University Extension Project called "Social Conflicts and Human Rights" as a way of applying the Multiport Justice System. In summary, it concludes that the Multiport Justice System can be an effective tool to meet the interests of the subjects in conflict from the opening of new ways to conceive the intersubjective conflicts, presenting the activities of the University Extension Project as experiences of a Multiport Justice System.

Keywords: Multiport system. Justice. Conflicts. University extension.

\section{SUMÁRIO}

1 Introdução. 2 Conflito, jurisdição e o Sistema Multiportas de Justiça. 3 A atuação do projeto de extensão "Conflitos sociais e direitos humanos" como experiência de um Sistema Multiportas de Justiça. 4 Conclusão. 5 Referências. 


\section{INTRODUÇÃO}

O poder Judiciário encontra-se atualmente em crise, perdendo sua legitimidade perante a sociedade. Por sua vez, a resposta tradicional ao conflito tem sido uma das causas permanentes da atual crise, reverberando em práticas violentas e desprovidas de diálogo e empatia.

O Sistema Multiportas de Justiça, não tão novo, mas pouco difundido no meio jurídico, tem ganhado gradativamente seu espaço na cena jurisdicional, pois oferece ferramentas de resolução de conflitos eficazes e céleres, trazendo satisfação aos envolvidos, não só por resolver a questão, mas principalmente por criar uma cultura de diálogo, não agressiva, e uma escuta ativa e respeitosa perante opiniões discrepantes, as quais são inerentes a uma interação conflitiva.

Nesse sentido o trabalho, além de investigar as causas da crise do paradigma clássico de Justiça, destacando a importância da promoção de práticas que permitam o despertar de novos olhares acerca dos conflitos intersubjetivos, também propõe-se a examinar a atuação do projeto de extensão "Conflitos Sociais e Direitos Humanos" da Universidade Regional do Noroeste do Estado do Rio Grande do Sul - Unijuí - em paralelo com as práticas de judicialização de conflitos desenvolvidas no Laboratório de Práticas Jurídicas da mesma Universidade, como experiência de um Sistema Multiportas de Justiça.

\section{CONFLITO, JURISDIÇÃO E O SISTEMA MULTIPORTAS DE JUSTIÇA}

O poder Judiciário encontra-se em crise, tanto quantitativa como qualitativa. As principais causas desta crise situam-se na demora para a resolução dos processos, bem como na cultura da dependência da decisão, aguardando as partes em conflito por uma resposta advinda de um terceiro, o juiz. Sendo assim, pode-se observar que a crise do paradigma clássico de Justiça está diretamente interligada com o modo como os conflitos são tradicionalmente tratados em sociedade, pois, em geral, as pessoas não conseguem dialogar a respeito de seus problemas e tentar resolvê-los de uma forma pacífica, criando, consequentemente, um cenário de violência e um Judiciário cada vez mais superlotado de demandas judiciais. Diante de todas estas situações, Ana Carolina Ghisleni (2018, p. 14) observa que:

As deficiências que o Estado enfrenta provocam inicialmente uma crise de identidade, que consiste na perda ou diminuição de seu poder decisório, aliada à crise de eficiência, que se traduz na dificuldade de oferecer retorno eficiente à conflituosidade social e aos litígios processuais.

Sendo assim, é possível observar que a crise do Judiciário vai além dos números. O processo judicial meio tradicional pelo qual o conflito é enfrentado - não consegue mais satisfazer a população por meio de suas sentenças, perdendo, assim, confiança, legitimidade e não asseverando garantia aos seus assistidos. "O maior problema da magistratura é que ela decide litígios que lhe são alheios, não levando em consideração, salvo raras exceções, o que as partes sentem e suas expectativas" (GHISLENI, 2018, p. 26).

Diz-se que tal crise encontra sua origem, principalmente, na litigiosidade desenfreada existente na sociedade, ou seja, os conflitos estão sendo consideravelmente uma marca muito presente nos diferentes modos de interação social e as pessoas não estão mais conseguindo administrá-los de forma responsável, necessitando, assim, que um terceiro (juiz) decida qual o melhor caminho a tomar.

Para dar conta do volume crescente de conflitos que chegam ao Judiciário é imprescindível que este se modernize, tanto estruturalmente, para atuar de maneira mais efetiva nos conflitos e oferecer uma resposta mais eficiente aos jurisdicionados, como também paradigmaticamente, aceitando de modo pacífico e integrador outras formas alternativas de enfrentamento de conflitos (MARZINETTI, 2018), o que passa fundamentalmente pela promoção de uma cultura de paz e de autonomia das partes em relação à solução de suas divergências, além da compreensão do conflito como algo positivo, inerente à vida em sociedade, mas sobretudo como um laço complexo que une dois ou mais sujeitos.

Em razão de diferentes fatores que passeiam entre o reconhecimento jurídico de grupos e de classes sociais, o desvelamento de novos atores sociais e os avanços das tecnologias digitais, em especial as de caráter informacional, os conflitos intersubjetivos têm ganhado contemporaneamente a marca da complexidade. 
Vive-se, atualmente, em um tempo em que a capacidade para formular soluções ou resolver questões é infinitamente menor do que a capacidade de produzir riscos e problemas. Do paradoxo entre o tempo e o Direito funda-se o descompasso entre a demanda e a resposta jurisdicional, agravado pela crescente necessidade da presença ativa de um Judiciário constitucionalmente mais comprometido com as questões sociais. Como acentua Rocha (2001, p. 134), "temos uma racionalidade jurídica tradicional de repetição [...] e, ao mesmo tempo, temos necessidade de tomar decisões mais sociais, mais políticas, levando-se em consideração o novo tempo da sociedade, sociedade do futuro". No âmbito do Judiciário, em razão do paradoxo entre tempo e Direito, este precisa fazer-se mais plural, voltado à produção e ao reconhecimento da diferença, e não tão somente à reprodução das fórmulas antecedentes, o que significa incorporar uma racionalidade complexa para pensar o fenômeno jurídico.

O conflito, sob esse viés, pode ser visualizado de forma positiva ou negativa no que diz respeito à sociedade e às relações interpessoais. Como um possível conceito da palavra conflito, vale destacar o adotado por Norberto Bobbio, Nicola Matteucci e Gianfranco Pasquino (1998, p. 225). Segundo os autores, o conflito pode ser tomado como "uma forma de interação entre indivíduos, grupos, organizações e coletividades que implica choques para o acesso e a distribuição de recursos escassos", ou seja, o conflito é uma forma de interação humana e social e é inerente à sociedade.

Por outro lado, o conflito, quando visualizado de forma negativa, pode ser entendido como um confronto de ideias e pensamentos, os quais, ao final, podem conduzir à violência - nas suas mais diversas concepções, seja física, moral, psicológica - visto que a sociedade contemporânea vem se individualizando cada dia mais, perdendo assim o exercício de conviver em comunidade e de ouvir e entender posicionamentos contrários. Nessa perspectiva, ao retornar à convivência coletiva, os conflitos sob seu viés negativo e as oposições de ideias começam a surgir.

Esse conflito, porém, por mais simples que possa ser, não consegue ser administrado e, com grande probabilidade, será encaminhado ao poder Judiciário, para que um terceiro decida qual o rumo a tomar e quem é o vencedor e o perdedor daquele confronto de ideias.

O conflito sob uma perspectiva positiva, por sua vez, consiste na compreensão de que ele faz parte do "ser sociedade" e "viver conjuntamente", possibilitando as evoluções do indivíduo como parte de um coletivo e como um ser pensante e racional. Pode-se dizer, assim, que o conflito ao gerar o confronto de ideias e opiniões constitui-se como um ato de reconhecimento e transformação das relações que se originarão daquele momento, influenciando e qualificando, assim, o movimento das interações humanas (SPENGLER, 2008). Desse modo, o conflito pode ser considerado uma característica incorporada e pertencente às relações interpessoais, buscando a evolução de cada indivíduo e não necessitando ser reputado como traço de instabilidade ou rompimento de vínculos sociais, mas sim como a possibilidade de uma integração social (SPENGLER, 2008).

Ainda assim, é possível verificar que ao analisar o conflito como algo positivo na sociedade e nas relações intersubjetivas, ele pode ser processado de uma forma muito mais pacífica e com a construção de um diálogo consideravelmente menos agressivo.

Destarte, a partir de toda crise vivenciada pelo poder Judiciário, bem como das questões conflitivas existentes e que trazem relação direta ao fato incialmente mencionado, pode-se afirmar que o direito básico de acesso à Justiça vem sendo comprometido significativamente a toda a população, principalmente à faixa populacional com menor acesso à educação e desprovida de condições financeiras para acessar o poder Judiciário. É nesse sentido que advém a necessidade de repensar as formas como esse direito está sendo aplicado e de fato efetivado para toda a sociedade, encontrando meios e soluções práticas para solucionar este problema. Nesse sentido, Mauro Cappelletti e Bryant Garth (1988) apresentam três soluções básicas para a efetividade de um acesso à Justiça pleno, utilizando-se da expressão "ondas de acesso à Justiça", criada a partir do Projeto de Florença e mencionam que:

Podemos afirmar que a primeira solução para o acesso - a primeira "onda" desse movimento novo - foi a assistência judiciária; a segunda dizia respeito às reformas tendentes a proporcionar representação jurídica para os interesses "difusos", especialmente nas áreas da proteção ambiental e do consumidor; e o terceiro - e mais recente - é o que nos propomos a chamar simplesmente "enfoque de acesso à Justiça" porque inclui os 
posicionamentos anteriores, mas vai muito além deles, representando, dessa forma, uma tentativa de atacar as barreiras ao acesso de modo mais articulado e compreensivo (CAPPELLETTI; GARTH, 1988, p. 31, grifo do autor).

Assim, essa terceira onda destacada trata-se resumidamente da criação e efetivação das formas alternativas de resolução de conflitos e consequentemente de um Sistema Multiportas de Justiça, capaz de abarcar todas as questões conflitivas existentes, bem como auxiliar na crise do poder Judiciário e consequentemente, garantir um acesso à Justiça pleno e eficaz para toda a população. É conveniente afirmar que essa terceira onda "centra sua atenção no conjunto geral de instituições e mecanismos, pessoas e procedimentos utilizados para processar e mesmo prevenir disputas nas sociedades modernas" (CAPPELLETTI; GARTH, 1988, p. 67-68).

Outrossim, no processo de instituição de políticas públicas que acenem no sentido do reconhecimento do viés positivo dos conflitos intersubjetivos, bem como das formas alternativas de resolução de conflitos, o Conselho Nacional de Justiça (CNJ) tem se constituído como um ambiente de promoção dessas formas consensuais e alternativas de resolução de conflitos, visto que por meio da publicação da Resolução no 125 de 29 de novembro de 2010, dispôs e regulamentou, pela primeira vez, a mediação e conciliação em âmbito brasileiro, instituindo a Política Judiciária Nacional de Tratamento adequado dos Conflitos de Interesses no âmbito do Judiciário. Nesse sentido, destaca Daniela Monteiro Gabbay (2011, p. 11) que no Brasil, o CNJ tem

determinado que os órgãos judiciários ofereçam, além da solução adjudicada mediante sentenças dos juízes, mecanismos de resolução consensual de controvérsias entre as partes, bem como a prestação de atendimento e orientação aos cidadãos, incentivando a autocomposição de litígios e a pacificação social por meio da conciliação e mediação.

Por meio desta resolução, o CNJ assumiu a competência para organizar programas que promovam e incentivam a autocomposição de conflitos, bem como levou à criação de Núcleos Permanentes de Métodos Consensuais de Solução de conflitos (Nupemec) e ao fomento dos Centros Judiciários de Solução de Conflitos e Cidadania (Cejusc).

Mais tarde, especificamente no ano de 2015, os meios alternativos de resolução de conflitos ganharam ainda mais força e aplicabilidade legal, visto que entraram em vigor duas novas leis que dispõem acerca da mediação e da conciliação de conflitos, ou seja, a Lei no 13.105/2015, denominada de Novo Código de Processo Civil, e a Lei no 13.140/2015, intitulada de Lei de Mediação.

É possível, então, perceber no contexto normativo brasileiro e nas práticas judiciárias mais recentes, principalmente a partir da terceira onda de acesso à Justiça, a instauração de um novo pensamento em relação aos conflitos interpessoais e aos modos de sua resolução, ou seja, um sistema de acolhimento de conflitos que oferece ao jurisdicionado uma diversidade de possibilidades de enfrentamento e que pode ser identificado como um Sistema Multiportas de Justiça. Nas palavras de Luis Fernando Guerrero (2012, p. 13, grifo do autor) o Sistema Multiportas

é uma tendência, não necessariamente nova, de se buscar formas de solução de conflitos que possam coexistir ou até mesmo fazer as vezes do tradicional sistema judicial de solução de conflitos. Essas formas podem ser realizadas a partir de uma postura amigável ou adversarial das partes.

Assim este sistema, e de forma mais específica as formas alternativas de resolução de conflitos, surgem como terceira onda de acesso à Justiça e possuem por escopo auxiliar na crise sofrida pelo poder Judiciário e tornar a resposta judicial mais célere, eficaz e adequada, ampliando o efetivo acesso à Justiça. A expressão "Sistema Multiportas de Justiça" (multidoor courthouse system) foi criada pelo professor Frank Sander, da Escola de Direito da Universidade de Harvard, no ano de 1976, com o argumento de que com o conflito sendo tratado de forma adequada, será possível a utilização eficiente dos recursos pelos tribunais, reduzindo custos e tempo de um processo normal e, consequentemente, diminuindo a ocorrência de conflitos subsequentes, visto que o objetivo precípuo do Sistema Multiportas é a solução real da discordância causada pelo conflito (GIMENEZ, 2017).

Destarte, pode-se elencar como possibilidades de um Sistema Multiportas de Justiça, além da heterocomposição (um terceiro que decide), as formas de autocomposição do conflito, sejam elas a conciliação, a negociação, a mediação e a justiça restaurativa, possibilitando aos conflitantes alternativas de resolução de 
seus conflitos, garantindo uma maior satisfação, sem privar o jurisdicionado do acesso a qualquer de suas portas. Entre as possíveis modalidade resolutivas de conflitos estão a conciliação, a negociação, a mediação e a justiça restaurativa.

A conciliação trata-se de uma forma autocompositiva voluntária, pois os envolvidos no conflito, juntamente com o conciliador, buscam chegar a um acordo favorável para ambos. Tem como objetivo principal o acordo, ou seja, o conciliador tem o poder de se manifestar apontando qual a melhor opção aos conflitantes.

Portanto, a conciliação é uma atividade mediadora direcionada ao acordo, qual seja, tem por objetivo central a obtenção de um acordo, com a particularidade de que o conciliador exerce leve ascendência hierárquica, pois toma iniciativas e apresenta sugestões, com vistas à conciliação (VASCONCELOS, 2017, p. 65).

Vale ressaltar que a conciliação ocorre preferencialmente nos casos em que os envolvidos não possuem vínculo social e afetivo anterior ou posterior ao conflito, pois seu maior objetivo é o acordo entre ambos e não a recomposição de relações interpessoais. Assim, para muitos, a conciliação pode ser confundida com a mediação, pois ambas têm a atuação de um terceiro facilitador e na maioria das vezes têm como resultado um acordo, mas de forma objetiva a conciliação

[..] é prevalentemente focada no acordo. É apropriada para lidar com relações eventuais de consumo e outras relações casuais - pessoas sem vínculos anteriores - em que não prevalece o interesse comum de manter um relacionamento, mas, fundamentalmente, o objetivo de equacionar interesses materiais ou questões jurídicas (VASCONCELOS, 2017, p. 64).

A conciliação pode ser pré-processual (realizada antes do processo) e/ou processual (durante o processo), ou ainda em alguns casos, ser realizada mesmo depois de já proferida uma sentença.

A negociação, por sua vez, consiste na prática de autocomposição, mas sem a presença de um terceiro facilitador, sendo conduzida diretamente pelos próprios conflitantes, ou seja, representa a autocomposição direta, justamente pelo fato de não contar com a interferência de um terceiro imparcial. Assim, como as demais formas, esta também baseia-se na voluntariedade e na consensualidade dos envolvidos, caso contrário não surtirá efeitos. Os negociantes é que irão conduzir e controlar o desenvolvimento e a forma de como irão chegar a um acordo, buscando sempre uma comunicação não violenta e a não imposição de interesses de um para o outro. "Qualquer solução dependerá única e exclusivamente da vontade e da atuação das partes por meio de uma solução consensuada, que de nenhum modo será influenciada ou facilitada por terceiro" (GUERRERO, 2012, p. 31-32).

Este método alternativo de resolução de conflitos pode ser considerado como sendo "o planejamento, a execução e o monitoramento, sem a interferência de terceiros, envolvendo pessoas, problemas e processos, na transformação ou restauração de relações, na solução de disputas ou trocas de interesses" (VASCONCELOS, 2017, p. 60). Ela sempre deve ser cooperativa e buscar um acordo que contemple todos os interesses envolvidos, com ganhos de forma mútua, uma vez que não tem por escopo eliminar ou derrotar o outro negociante.

Ainda vale ressaltar que a negociação deve sempre ser baseada em alguns princípios que servem como base, com destaque para o princípio da cooperação, visto que seu objetivo é integrar as pessoas envolvidas, mas jamais eliminar, derrotar ou excluir a outra parte (VASCONCELOS, 2017).

A mediação trata-se de um método consensual de resolução de conflitos, no qual um terceiro facilitador auxilia os mediandos a restabelecer o diálogo e a criar uma nova cultura de paz, tendo como uma possível consequência o acordo. O mediador não pode, em momento algum, interferir no conflito, sugerindo modos para seu encaminhamento; deve, tão somente, conduzir o diálogo, valendo-se de técnicas e meios para que os envolvidos consigam conversar de uma forma não violenta e pensando no bem comum.

É muito importante e eficaz o mediador encontrar os pontos comuns que os mediandos possuem, trabalhando assim sobre esses critérios e desenvolvendo uma concepção positiva do conflito, de modo que os envolvidos possam implicar-se com a questão e também uns com os outros, analisando e interpretando o conflito com diferentes pontos de vista. "Cabe, portanto, ao mediador, com ou sem a ajuda do comediador, colaborar com os mediandos para que eles pratiquem uma comunicação construtiva e identifiquem seus interesses e necessidades comuns" (VASCONCELOS, 2017, p. 61). 
Vale ressaltar que o objetivo da mediação não é chegar ao acordo, mas sim restabelecer o diálogo entre os envolvidos no conflito e recompor os laços afetivos e sociais existentes entre ambos. $O$ acordo é considerado apenas uma consequência da qualificação comunicativa entre os envolvidos no processo de identificação mediada de interesses. Nesse sentido é importante destacar o posicionamento de José Luis Bolzan de Morais e Fabiana Marion Spengler (2008, p. 134):

Com o auxílio do mediador, os envolvidos buscarão compreender as fraquezas e fortalezas de seu problema, a fim de tratar o conflito de forma satisfatória. Na mediação, por constituir um mecanismo consensual, as partes apropriam-se do poder de gerir seus conflitos, diferentemente da Jurisdição estatal tradicional na qual este poder é delegado aos profissionais do direito, com preponderância àqueles investidos das funções jurisdicionais.

Ainda, é possível identificar na mediação características que a diferenciam das demais práticas alternativas de resolução de conflitos, entre as quais pode-se citar: a) a privacidade, visto que ela ocorre de modo sigiloso e somente haverá divulgação do que foi dito se assim os mediandos quiserem; b) a economia financeira e de tempo, pois os litígios levados à mediação normalmente são resolvidos em um tempo consideravelmente menor pelo fato de prevalecer a vontade dos envolvidos, o que consequentemente acarretará na sua diminuição de custo; c) a oralidade, uma vez que esta não possui uma forma de acontecer, ela apenas vai sendo conduzida pelo mediador, que vai ter de encontrar o melhor meio a ser seguido, diante da situação em que ele estiver, pois cada caso e cada conflito podem ser solucionados de diferentes formas; d) a reaproximação das partes, considerada a maior característica da mediação, visto que ela é justamente utilizada para restabelecer o diálogo rompido e fortalecer os laços que foram destruídos com o conflito em questão; e) a autonomia das decisões, dado que os mediandos é que decidirão qual o futuro daquela mediação e do conflito em si, o qual uma vez autocomposto, pode ou não ser levado à homologação judicial; f) o equilíbrio das relações entre as partes, porquanto os mediandos devem ser ouvidos e ter momentos de fala de forma igualitária, jamais um sendo favorecido perante o outro, ou seja, o mediador deve ser totalmente imparcial (MORAIS; SPENGLER, 2008).

No que diz respeito à Justiça Restaurativa, esta possui natureza de caráter interdisciplinar na prevenção e no tratamento de assuntos com base criminal e no âmbito brasileiro sua prática é muito recente. Ela também é reconhecida como uma forma alternativa de resolução de conflito, apenas sob um viés e olhar diferenciado das demais, tendo em vista tratar de assuntos com base criminal. Seu conceito também é considerado muito amplo e de difícil definição, mas atualmente entende-se como um instrumento/técnica em que a vítima, o ofensor e possivelmente pessoas da comunidade atingidas pelo cometimento do crime buscam por meio do diálogo encontrar uma solução para todas as questões surgidas com tal delito, cada uma expondo seus sentimentos e razões para tal acontecimento. Assim, a Justiça Restaurativa apresenta-se como uma

nova forma de lidar com a questão dos conflitos e dos crimes, centrada mais nas pessoas e nos relacionamentos do que nas questões jurídicas. Antes que discutir questões legais, culpados e punições, a JR promove intervenções focadas na reparação dos danos, no atendimento das necessidades da vítima, na corresponsabilização do ofensor, sua família e pessoas do seu relacionamento, tudo visando à recomposição do tecido social rompido pela infração e o fortalecimento das comunidades (A PAZ..., 2019).

As práticas de Justiça Restaurativa são normalmente conduzidas por um terceiro facilitador (mediador) e tem por escopo lidar com o ato infracional de uma maneira diferente das formas tradicionais. Assim, este método alternativo de resolução de conflitos tem um modo de acontecer, pois está baseado em valores e possui procedimentos que devem ser seguidos, tendo como principal caraterística a voluntariedade, ou seja, "a prática restaurativa só acontecerá se for do consentimento de ambas as partes, e o mesmo não podem surgir a partir de uma tentativa de vantagem no processo penal" (GOLART; MAIER, 2019). Ou seja, este método busca integrar o processo penal, como uma forma também de ressocializar o autor de um fato delituoso, para que este possa retornar à sociedade, após ser responsabilizado pelo que fez e possuindo melhor aceitação pelos demais envolvidos no conflito.

Por fim, cabe ressaltar que esta opção de tratamento de conflitos de natureza penal não substitui as demais formas tradicionais de enfrentamento e repressão da criminalidade, apenas traz um novo olhar sobre o conflito e os conflitantes, com o escopo de entender e reavaliar as questões que envolvem este tipo de controvérsia. Nesse sentido, já afirmava Howard Zehr (2008, p. 168) que 
a escolha da lente afeta aquilo que aparece no enquadramento da foto. Determina também o relacionamento e proporção relativa dos elementos escolhidos. Da mesma forma, a lente que usamos ao examinar o crime e a justiça afeta aquilo que escolhemos como variáveis relevantes, nossa avaliação de sua importância relativa e nosso entendimento do que seja um resultado adequado.

Ou seja, ao analisar o crime com as lentes retributivas, modelo tradicional de enfrentamento deste tipo de conflito, não se faz possível atender a todas as necessidades da vítima e do ofensor. O processo acaba por se tornar negligente, uma vez que se preocupa apenas em responsabilizar os ofensores e coibir o crime, sem se preocupar com o atendimento aos sentimentos e emoções das vítimas (ZEHR, 2008).

Assim, pode-se afirmar que o motivo de toda esta incapacidade judiciária está na escolha das lentes utilizadas. Para Zehr (2008), existem duas lentes distintas, que podem, ao ser escolhidas de forma correta, proporcionar novos rumos ao processo penal brasileiro, ou seja, nas lentes da Justiça Retributiva o crime é visto sob a ótica de um atentado "contra o Estado, definida pela desobediência à lei e pela culpa. A justiça determina a culpa e inflige dor no contexto de uma disputa entre ofensor e Estado, regida por regras sistemáticas" (ZEHR, 2008, p. 170). Já no que diz respeito às lentes da Justiça Restaurativa, esta considera o crime como uma forma de violar as pessoas e seus relacionamentos. "Ele cria a obrigação de corrigir os erros. A Justiça envolve a vítima, o ofensor e a comunidade na busca de soluções que promovam reparação, reconciliação e segurança" (ZEHR, 2008, p. 170-171).

A Justiça Restaurativa, desse modo, busca curar as partes envolvidas, seja os ofensores, que além de serem responsabilizados pelo crime cometido vão ser conduzidos a um caminho de mudança, seja as vítimas, que também precisam ser ouvidas, e a própria comunidade, que também é atingida com os reflexos desta relação afetada (ZEHR, 2008).

\section{A ATUAÇÃO DO PROJETO DE EXTENSÃO "CONFLITOS SOCIAIS E DIREITOS HUMANOS" COMO EXPERIÊNCIA DE UM SISTEMA MULTIPORTAS DE JUSTIÇA}

A Universidade Regional do Noroeste do Estado do Rio Grande do Sul - Unijuí - possui como prática de extensão vários projetos, com o intuito de se aproximar da comunidade local e regional, promovendo o desenvolvimento, mediante ações comunitárias, de prestação de serviço e de educação continuada.

Desse modo, é importante destacar que a Universidade possui três eixos fundamentais, que são o ensino, a pesquisa e a extensão. De tal modo, busca-se entender por meio deste trabalho, o eixo da Extensão, sobretudo no que tange ao curso de Direito da Unijuí, sua evolução histórica e, principalmente, como a integração dos projetos de extensão no âmbito do curso de Direito pode identificar-se com um Sistema Multiportas de Justiça, uma vez que oferece à população diferentes formas de resolução de conflitos.

Dos três eixos universitários, a extensão foi a última a ser instituída, uma vez que exige um maior envolvimento de pessoas e principalmente da aceitação da comunidade. As primeiras formas de extensão universitária surgiram na Inglaterra, em meados do século 19, consolidando-se posteriormente na Bélgica, na Alemanha e logo se estendendo para toda a Europa, chegando, por fim, aos Estados Unidos (EUA). Ao chegar aos EUA a extensão se difundiu de forma significativa, pois foi criada

[...] a American Society for the Extension of University Teaching, que impulsionou as atividades de extensão, pioneiramente, na Universidade de Chicago, em 1892, culminando na experiência desenvolvida pela Universidade de Wisconsin, em 1903, que colocou "seus professores como technical experts do governo do estado". Muito bem-sucedida, a iniciativa conferiu prestígio e visibilidade nacional ao que seria chamado de "Wisconsin Idea", levando o próprio presidente americano, Theodore Roosevelt, a sinalizar para o país aquele exemplo (PAULA, 2013, p. 7).

A extensão universitária brasileira, por sua vez, começou a ser difundida mais tarde, na primeira metade do século 20, e "é originária da união de escolas superiores isoladas, criadas por necessidades práticas do governo, por carências sentidas pela sociedade ou como resultado de avaliação sobre um potencial em uma ou outra área" (POLÍTICA E DIRETRIZES..., 2013, p. 7). 
A extensão na Unijuí teve seu surgimento no ano de 1956, conjuntamente com a criação da Faculdade de Filosofia, Ciências e Letras (Fafi), com o auxílio da articulação da comunidade regional, o que mais tarde permitiu a criação do Projeto Universitário. A extensão na Unijuí surge como um pilar de sustentação para a comunidade de seu entorno e com a criação da Fafi, essa preocupação social se intensificou, uma vez que era considerada espaço de realização solidária e coletiva (POLÍTICA E DIRETRIZES..., 2013, p. 7).

Mais tarde, iniciou-se um forte movimento e discussões para expandir o Ensino Superior na região, objetivando criar uma entidade regional, que fosse aberta e descentralizada, para assim conduzir esse ensino. Desse modo,

a presença marcante da Fafi na região, aguçada pelo Movimento Comunitário de Base, influenciou nas discussões para a criação de uma entidade regional, aberta e descentralizada, a fim de conduzir e respaldar a expansão do ensino superior na região. Em 1969 a Fafi reestrutura-se e passa a ser mantida pela Fundação de Integração, Desenvolvimento e Educação do Noroeste do Estado do Rio Grande do Sul (Fidene), com o propósito de encaminhar o projeto de universidade regional, dando o suporte legal, patrimonial e econômico-financeiro ao desenvolvimento do Ensino Superior no Noroeste do Estado. Com expansão da Instituição, as atividades de extensão universitária foram assumindo a forma de programas e projetos específicos (POLÍTICA E DIRETRIZES..., 2013, p. 8).

Por fim, em meados de 1981, foram criados os Centros Integrados de Ensino Superior de ljuí, e que em 1985 passaram a ser reconhecidos como Universidade de ljuí, tendo a estrutura que permanece até os dias atuais. A Universidade de ljuí, mais tarde, em 1994, renovou sua denominação, passando a chamar-se Universidade Regional do Noroeste do Estado do Rio Grande do Sul - Unijuí - a qual se mantém até hoje.

Durante toda essa evolução a extensão sempre se fez presente para a comunidade de ljuí e arredores, de forma a ser aplicada conforme as necessidades comunitárias que iam surgindo e à medida que os cursos iriam sendo instalados na Universidade. "As ações voltadas para a comunidade propiciaram à universidade, entendida como agente de mudanças, o desenvolvimento de conhecimentos, métodos e técnicas que permitiram enriquecer a formação acadêmica" (POLÍTICA E DIRETRIZES..., 2013, p. 8).

Inicialmente, a extensão no seio da Universidade Regional ocorreu por meio da realização de cursos, principalmente na área agropecuária e de processos produtivos, objetivando uma metodologia participativa da comunidade. Mais tarde, porém, as atividades de cursos foram ampliadas com ações educativas, junto de grupos sociais já constituídos, como agricultores, moradores de bairros, organizações populares, diversos sindicatos, entre outros. Por fim, a partir de programas institucionais, essas ações foram ampliadas e passaram a possuir temáticas mais abrangentes, envolvendo, por exemplo, saúde, economia, administração rural, pequenas empresas, para citar alguns (POLÍTICA E DIRETRIZES..., 2013, p. 8).

Tudo isso foi possível, uma vez que "a comunidade em que a Unijuí está inserida sempre apresentou um vasto laboratório, oportunizando contato com a realidade dos fatos, a vivência e a solução de problemas" (POLÍTICA E DIRETRIZES..., 2013, p. 8). A extensão nesta Universidade, sempre buscou refletir e captar o conhecimento e a cultura da população e da comunidade em que estão inseridas, para assim, e com base nisto, realimentar e conduzir o processo de ensino.

A partir de todos esses programas e evoluções é que a história de extensão da Unijuí se constituiu, visando sempre, além de todo aprofundamento e conhecimento científico, bem como conteúdo de ensino e laboratório, possuir a base social comunitária, uma vez que faz parte de sua origem. Além disso, cabe mencionar que a extensão na Unijuí é definida e tem por base cinco diretrizes, que foram aprovadas pelo seu ConseIho Universitário e que compreendem a extensão como:

a) espaço de interação acadêmica e dialógica com a sociedade que busca compreender e inserir-se no desenvolvimento regional, apontando problemas e potencialidades, e desenvolvendo-se de forma articulada com o Ensino e a Pesquisa;

b) prática de socialização, sistematização e produção de conhecimentos, que se dá de forma sistemática e continuada, de modo a promover mudanças desejadas pelos parceiros e resultar em produções teórico-metodológicas, técnico-científicas e artístico e/ou culturais;

c) prática comprometida com o desenvolvimento social dentro de uma perspectiva de inovação, sustentabilidade, qualificação tecnológica e inclusão social; 
d) ação não disciplinar, capaz de contribuir para a efetivação da democracia, a partir da problematização e da construção de alternativas para as questões locais e regionais, fortalecendo a emancipação social dos grupos envolvidos;

e) prática acadêmica submetida à avaliação sistemática para a identificação dos impactos produzidos na realidade social e acadêmica (POLÍTICA E DIRETRIZES..., 2013, p. 15).

Outrossim, no que diz respeito às práticas de extensão da Universidade, mais especificamente ao curso do Direito, tanto no Campus ljuí quanto nos campi de Santa Rosa e Três Passos, estão em atividade, atualmente, três Projetos de Extensão Universitária: "Cidadania para Todos", "Conflitos Sociais e Direitos Humanos: Alternativas Adequadas de Tratamento e Resolução" e "Resolução e Regularização Fundiária Urbana: Direito Social à Moradia Digna". Os dois primeiros já possuem vários anos de atuação e serão abordados a seguir. $O$ terceiro iniciou suas atividades em 2019 com a finalidade de conferir aos moradores/ocupantes de imóveis alocados em núcleos urbanos informais o título de propriedade, garantindo-lhes o direito à moradia digna e ao meio ambiente sadio e equilibrado.

O Projeto Cidadania para Todos, por sua vez, teve sua origem em 2006 e, desde então, vem exercendo sua atividade de modo constante. Possui como objetivo central promover a educação para os direitos humanos e para a cidadania, atuando com oficinas e palestras que têm por escopo o protagonismo dos participantes, organizadas a partir de grandes eixos temáticos que envolvam temas como violência, conflitividade e responsabilidade, gênero e sexualidade, direitos fundamentais, participação e democracia, inserção no mundo do trabalho e cidadania, além de debates acerca de modos adequados de utilização das ferramentas digitais (PROJETO DE EXTENSÃO..., 2018). A metodologia de intervenção deste Projeto consiste na realização de oficinas temáticas desenvolvidas com base em metodologias restaurativas, sessões de cinema e palestras, objetivando a interação dos envolvidos, a reflexão dos temas abordados e, principalmente, a vivência dos valores sociais.

Já o Projeto Conflitos Sociais e Direitos Humanos: alternativas adequadas de tratamento e resolução iniciou suas atividades em meados de 2012, no Campus Santa Rosa, buscando, por meio das práticas de mediação, auxiliar os assistidos do Núcleo de Prática Jurídica a encontrar meios de administrar suas divergências de natureza familiar. Mais tarde, os demais campi iniciaram suas atividades junto ao Projeto, com destaque para a criação do Balcão do Consumidor de ljuí em 2014 e em Santa Rosa no ano de 2017, a expansão do Projeto com a adoção de metodologias de intervenção em conflitos escolares (PROJETO DE EXTENSÃO CONFLITOS..., $2019 \mathrm{~b}, \mathrm{~s} / \mathrm{p}$ ). Este Projeto tem como objetivo principal, a aplicação de modos alternativos de resolução de conflitos e será analisado de modo mais detalhado a seguir, uma vez que pode ser identificado como uma experiência de Sistema Multiportas de Justiça.

O Projeto de Extensão Conflitos Sociais e Direitos Humanos: alternativas adequadas de tratamento e resolução - 2018/2019a, menciona que é seu intuito

[...] a integração entre a Universidade e a comunidade externa das cidades de ljuí, Santa Rosa, Três Passos, além de englobar as respectivas regiões, fomentando a criação e a qualificação dos espaços públicos que garantam o exercício da cidadania, assim como ações individuais e coletivas de efetivação de práticas alternativas de solução de conflitos, em especial os vinculados às relações familiares, patrimoniais, de consumo e as estabelecidas no âmbito escolar.

Desse modo, pode-se afirmar que o Projeto possui uma grande importância social, uma vez que é visível a necessidade de criação e fomento de espaços que contemplem a resolução alternativa dos conflitos sociais de forma mais célere, eficaz, e que observem as necessidades das partes, tendo em vista a crise atual experimentada pelo poder Judiciário. Assim, o Projeto oferece à comunidade "novas estratégias de tratar os seus conflitos que, paralelamente ao Judiciário, poderão oferecer respostas mais apropriadas quantitativa e qualitativamente" (PROJETO DE EXTENSÃO CONFLITOS..., 2019d, s/p).

Dessa forma, apresenta-se como justificativa central para a instituição do Projeto antes mencionado, além de sua inegável importância social, a característica atual das ações que envolvem o poder Judiciário, nas quais grande parte dos processos versam acerca de questões familiares, patrimoniais e de consumo. É nesse 
sentido que o Projeto, ao desenvolver mediações, conciliações e negociações pré-processuais, auxilia na redução do congestionamento do poder Judiciário, bem como oferece uma resposta mais célere, eficaz e, sem dúvida, menos desgastante aos envolvidos.

A atuação do Projeto se dá de três modos diferentes, porém todos voltados à solução pacífica, dialogada e consensual dos conflitos. Primeiro, nos Escritórios Modelos do Curso de Direito, acolhendo as demandas trazidas pela comunidade e quando verificada a possibilidade de aplicação das técnicas alternativas e adequadas de solução de controvérsias, o encaminhamento para realização de mediações e/ou conciliações pré-processuais. Segundo, no atendimento e acolhimento de questões conflitivas trazidas pelos consumidores aos Balcões de Consumidores, nos três campi, com a possibilidade da negociação ou, ainda, conciliação. Por fim, com a atuação do Projeto na rede pública de ensino, a fim de auxiliar na resolução de questões conflitivas existentes em âmbito escolar.

Diante de todas essas formas de atuação, pode-se afirmar que o Projeto visa, a partir da utilização de métodos alternativos de resolução de conflitos, a aproximar todas as partes envolvidas em um conflito, devolvendo a elas a autonomia e responsabilidade de enfrentamento das questões trazidas, bem como capacitando-as para enfrentarem o conflito de modo construtivo e não violento.

Nesse sentido, vale destacar a atuação do Projeto em cada campus, de modo específico. As execuções do Projeto no Campus Santa Rosa, por meio das Mediações Familiares e Escolares e do Balcão do Consumidor, se dão principalmente com o atendimento ao público e às escolas. No que tange às atividades realizadas nas escolas, são realizadas palestras sobre novas perspectivas para a gestão de conflitos escolares. Já no que diz respeito ao Balcão do Consumidor e à mediação familiar, estes possuem atendimento ao público no mesmo espaço físico do Escritório de Práticas Jurídicas do Curso de Direito, tendo como propósito permitir também que os acadêmicos estagiários tenham contato com diferentes formas de solução e enfrentamento de conflitos, uma vez todos os atendimentos feitos pelo Projeto de Extensão possuem auxílio de alguns alunos matriculados no Estágio Supervisionado, nos respectivos turnos de atendimento. Desse modo, o assistido do Escritório Modelo é inicialmente recepcionado pela secretária do escritório que, após uma breve avaliação da natureza da demanda - para verificar se são passíveis de mediação, ajustáveis ao contencioso ou vinculadas às relações de consumo - faz os devidos encaminhamentos, direcionando os casos, respectivamente, para as mediações familiares, atendimento nos grupos do Estágio Supervisionado ou para o Balcão do Consumidor. Outrossim, nos campi de ljuí e Três Passos as atividades são realizadas no Balcão do Consumidor e no Estágio no Núcleo de Práticas Jurídicas.

A partir deste momento, será abordado de forma mais específica a atuação do presente Projeto no Campus de Santa Rosa, com a explanação e abordagem das atividades realizadas no Balcão do Consumidor e de práticas de Mediação Familiar e Mediação Escolar.

O Balcão do Consumidor é um meio de garantir a aplicabilidade dos direitos básicos do consumidor. A Universidade Regional, no Campus de Santa Rosa, possui como prática de extensão universitária, o Balcão do Consumidor, que está em atividade desde o segundo semestre de 2018, junto ao Núcleo de Prática Jurídica e atende toda população do município de Santa Rosa/RS, principalmente a população idosa, de forma gratuita, a fim de tentar resolver uma questão conflitiva referente à uma relação de consumo.

A Universidade, por intermédio do curso de Direito do Campus de Santa Rosa, possui uma parceria com o Procon do Estado do Rio Grande do Sul, denominada "Protocolo de Intenções para Criação do Balcão do Consumidor na Universidade Regional do Noroeste do Estado do Rio Grande Do Sul - Campus Santa Rosa", que teve como intuito principal a criação do Balcão do Consumidor, vinculando-o ao Projeto de Extensão Conflitos Sociais e Direitos Humanos: alternativas de tratamento e resolução, e ao próprio Escritório Modelo do Curso de Direito da Unijuí - Campus de Santa Rosa, a fim de fornecer atendimento, prestar esclarecimentos aos consumidores e envolver os acadêmicos bolsistas do projeto e estagiários do Escritório Modelo na busca de soluções consensuais para os conflitos de consumo.

Tendo em vista que o atendimento ocorre no mesmo espaço físico do Escritório de Práticas Jurídicas do Curso de Direito (também denominado de Escritório Modelo) e que o propósito também é permitir que os acadêmicos estagiários tenham contato com diferentes formas de solução e enfrentamento de conflitos, todos os atendimentos realizados no Balcão do Consumidor são o resultado de uma parceria entre o bolsista 
do projeto, a professora responsável e os estagiários do Escritório Modelo matriculados no respectivo turno de atendimento, os quais auxiliam desde o acolhimento da demanda até os encaminhamentos necessários à tentativa de resolução extrajudicial do conflito de consumo.

Em termos procedimentais o atendimento do Balcão do Consumidor consiste inicialmente numa prévia análise do caso relatado para verificar se se trata realmente de uma relação de consumo. Este momento é denominado de triagem. Posteriormente, mediante a confirmação de se tratar de uma relação de consumo é feito um cadastro prévio com os dados pessoais do consumidor e do(s) fornecedor(es) junto ao Sindec (Procon-RS), que consiste num sistema de integração nacional de ações e informações relativas à defesa do consumidor. Após o acolhimento do consumidor e a elaboração do cadastro, o próprio consumidor inicia seu relato de forma bem detalhada, o qual é devidamente registrado pelo bolsista no sistema antes mencionado.

Sendo assim, nos casos em que se verifica a possibilidade de um prévio contato telefônico com o fornecedor, este é realizado buscando resolver da forma mais fácil, rápida e amigável possível a questão suscitada, momento este em que muitas demandas já são solucionadas graças a esta intermediação. No caso de êxito neste contato telefônico, o atendimento é encerrado e fornecido um espelho da ficha de atendimento ao cliente com todas as informações prestadas pelo consumidor e pelo fornecedor, configurando assim o chamado atendimento preliminar.

Caso o atendimento preliminar não possua eficácia, ou não seja o caso de sua realização, uma vez que alguns fornecedores não têm a possibilidade de um contato por telefone ou setor responsável para atendimento ao público, é enviada uma CIP - Carta de Informações Preliminares - ao fornecedor, relatando o que o consumidor informou, inclusive com a síntese das informações prestadas pelo próprio fornecedor no atendimento preliminar, quando for o caso.

A CIP é elaborada com a fundamentação jurídica e legal da pretensão do consumidor, além da solicitação específica para a solução do caso e a apresentação de documentação relativa à relação de consumo, a qual em geral não foi previamente entregue ao consumidor quando da celebração do contrato. A CIP é assinada pela coordenadora do Balcão do Consumidor e pelo próprio consumidor, podendo ser enviada via Correio, mediante Carta Física com AR, ou por e-mail integrado ao Sistema Sindec, nos casos em que o fornecedor possui o convênio para o envio de CIP Eletrônica. Assim, nos casos em que é necessário o envio de CIP, o fornecedor tem o prazo de 10 dias, a contar da data de seu recebimento, para enviar uma resposta e apresentar o seu posicionamento sobre o caso.

Recebida a resposta, o consumidor é convidado a retornar ao Balcão para seu recebimento e devidas explicações e orientações sobre o conteúdo da resposta do fornecedor. Nessa ocasião, dependendo da disponibilidade do fornecedor à composição amigável, poderá ser celebrado acordo ou agendada uma sessão de conciliação entre consumidor e fornecedor, a qual é intermediada pela professora coordenadora do Balcão. No caso da possibilidade da realização desta sessão de conciliação e as partes concordando em participar, é feita uma ata durante a sua realização, relatando tudo que ocorreu na sessão e se resultou ou não em acordo, a qual posteriormente é assinada por todos os presentes e entregue uma cópia para cada participante.

Já, em se tratando de resposta negativa ao acordo ou composição, a CIP é encerrada e o consumidor, quando for o caso, é orientado a procurar atendimento jurídico particular, pela Defensoria Pública ou pelo próprio atendimento do Escritório Modelo nos casos em que o consumidor anteriormente atendido pelo Balcão do Consumidor, mas que não conseguiu resolver sua demanda por lá e necessita ingressar judicialmente. Sendo assim, o atendimento é encerrado sem resolução do caso e baixado com a observação de que o consumidor foi orientado a ingressar judicialmente.

Por fim, existe também a possibilidade de um atendimento apenas de cunho educativo e informacional, que é denominado de Simples Consulta, no qual o consumidor busca o Balcão do Consumidor apenas para esclarecer dúvidas acerca de seus direitos e obrigações. Neste caso, embora se proceda com um registro do atendimento junto ao Sindec, nenhum contato com o fornecedor é realizado.

A Unijuí Campus de Santa Rosa, como mencionado anteriormente, também conta com a prática de mediações de conflitos pré-processuais e mediações escolares, práticas de extensão relacionadas ao Projeto Conflitos Sociais e Direitos Humanos. 
A mediação familiar começou a ser realizada antes mesmo da formalização do Projeto supracitado, com a iniciativa da professora Francieli Formentini, juntamente com alguns alunos voluntários do curso de Direito junto ao Espaço do Núcleo de Prática Jurídica da Unijuí - Campus de Santa Rosa (Escritório-Modelo), por volta do ano de 2012, tendo como principal intuito a efetivação de formas alternativas de resolução de conflitos. O público-alvo inicial era composto de assistidos do próprio Escritório Modelo, os quais eram encaminhados a uma mediação ou conciliação. Mais tarde, especificamente no ano de 2013, com a evolução das práticas alternativas de resolução de conflitos no Escritório Modelo, criou-se o Projeto, a fim de vinculá-lo à extensão universitária e consolidar todas as atividades que já vinham sendo desenvolvidas.

Atualmente as práticas de mediação e conciliação vêm sendo realizadas de modo constante no Núcleo de Prática Jurídica da Unijuí - Campus de Santa Rosa - com o auxílio das professoras responsáveis, bem como das bolsistas e estagiários matriculados nos componentes de Estágio Supervisionado. $\mathrm{O}$ atendimento ocorre por meio de várias etapas. A triagem consiste numa análise detalhada do caso, verificando se este realmente se encaixa nos critérios de renda para atendimento, se ainda não possui nenhum processo relacionado ao caso, uma vez que são realizadas mediações pré-processuais e por fim, se eles realmente possuem interesse em realizar a mediação e conversarem a respeito do caso, visto que um dos princípios básicos das formas alternativas de resolução de conflitos é a voluntariedade das partes envolvidas. Ainda, nessa oportunidade, é explicado ao mediando, sobre o que é e como funciona a mediação, bem como alguns princípios que servem como base, para que este entenda a mediação e possa de modo consciente e voluntário aderir a sua proposta.

Após a triagem e concordância de ambos os mediandos em participar da mediação, é realizada a sessão no dia e horário marcados, com a participação de todas as partes envolvidas, dos bolsistas do Projeto, da professora mediadora e de alguns alunos que estão realizando o Estágio Supervisionado no Núcleo de Prática Jurídica, os quais ocupam a posição de observadores, com o objetivo de lhes proporcionar o contato e conhecimento das formas alternativas de resolução e enfrentamento de conflitos.

A partir de então o mediador irá encaminhar a sessão de mediação, valendo-se da utilização de técnicas adequadas capazes de qualificar o diálogo entre os conflitantes e demonstrar todas as potencialidades criativas do conflito. Caso os mediandos componham um entendimento e desejando a redução a termo na forma de um acordo, o documento é elaborado, devidamente assinado pelo técnico do Núcleo de Prática e encaminhado para a homologação judicial, possuindo força de título executivo judicial. Por fim, os acordos realizados e já encaminhados ao poder Judiciário, são acompanhados pelas bolsistas até o trânsito em julgado da decisão de homologação judicial e, posteriormente, havendo necessidade, são levados a promoção dos registros competentes.

No que respeita às Mediações Escolares, estas vêm ocorrendo desde o ano de 2017, após demandas originadas dentro das escolas, as quais buscavam auxílio para lidar e trabalhar de forma positiva com os inúmeros conflitos que surgem em ambiente escolar. Assim, além de várias palestras realizadas em inúmeras escolas da região de Santa Rosa/RS a respeito da possibilidade da mediação escolar e, principalmente, da gestão e enfrentamento do conflito, o projeto tem trabalhado continuamente com a Escola Estadual Timbaúva, que fica no bairro da própria Universidade. O projeto, no decorrer de três anos de atuação, vem sendo desenvolvido em atenção às necessidades do grupo escolar e, sobretudo, no propósito de permitir a inauguração de novos olhares sobre as divergências de interesses que povoam o atual cenário escolar.

A primeira etapa consiste no diagnóstico e identificação da turma a ser trabalhada, uma vez que, a cada ano, uma turma específica é indicada para fazer parte do projeto pelo grupo de professores da escola, bem como pela equipe diretiva. Nesse mesmo momento são elaboradas e formatadas as oficinas gerais a serem trabalhadas durante o decorrer do ano, e uma posterior apresentação do planejamento ao conjunto de professores que ministram aulas para a turma e a toda equipe diretiva da escola. A segunda etapa, por sua vez, compreende a execução do projeto propriamente dito, ou seja, são realizados os encontros, com periodicidade quinzenal, com a turma a ser trabalhada.

No ano de 2017 a execução do projeto deu-se principalmente pela aplicação de círculos de diálogo com a turma, mas sem envolver muito a participação dos professores. Já em 2018 os encontros ocorreram por meio de oficinas e gincanas realizadas na própria escola, as quais foram antecipadamente elaboradas, levando em consideração interesses do grupo de alunos, mas de forma criativa, com o intuito de explicar como funciona a mediação de conflitos e qual o propósito de levar esse projeto ao âmbito escolar. No ano de 2019, o projeto foi realizado de um forma um pouco variada, no sentido de proporcionar à própria escola, professores e alunos, o protagonismo e autonomia em desenvolver atividades de propagação do diálogo e de formas alternativas 
de resolver os conflitos escolares. Ou seja, as professoras extensionistas e as alunas bolsistas fornecem todo o aparato técnico para o desenvolvimento das atividades, mas a aplicação ficará a cargo da escola e dos professores, proporcionando assim que todas as turmas e todos os professores sejam envolvidos nas atividades.

\section{CONCLUSÃO}

A abertura de uma nova janela para o pensamento jurídico, capaz de fazer frente aos conflitos, passa pela recuperação da humanidade no Direito, pelo resgate das subjetividades que foram relegadas em nome da segurança jurídica e de uma troca de lentes em relação às energias antagônicas presentes nos vínculos conflitivos, podendo vê-las como oportunidades criativas para encontrar o outro do conflito, invisível no paradigma individualista e egocêntrico (simplificador) da modernidade.

Nesse sentido, a janela que se abre para o novo no pensamento jurídico pressupõe a tomada de consciência acerca das complexidades humanas nas quais os conflitos judicializados ou não estão embebidos, e a necessidade de religar o que a racionalidade moderna separou, formando uma rede de múltiplas dimensões - do homem com o cosmo, com a natureza, com o outro homem e consigo mesmo - ocupada com a experimentação de formas de viver com mais qualidade de vida.

Assim, pode-se concluir que o Sistema Multiportas de Justiça é uma ferramenta que dispõe de várias formas de resolução de conflitos, uma vez que oferece aos envolvidos inúmeras portas, como mediação, conciliação, negociação, justiça restaurativa e, por fim, a demanda tradicional perante o poder Judiciário. Por outro lado é possível observar que a crise que o poder Judiciário sofre atualmente está além dos números, ou seja, não é apenas uma crise quantitativa, mas também qualitativa. O processo judicial (que é o meio tradicional pelo qual ele se manifesta) não consegue mais satisfazer a população por meio de suas sentenças, perdendo assim confiança, legitimidade e não assegurando a garantia da pacificação social aos seus jurisdicionados.

Como já mencionado, o Sistema Multiportas de Justiça consiste na possibilidade de usufruir de várias formas de resolução de conflitos, dando a oportunidade ao indivíduo de escolher o meio mais adequado para resolver sua questão particular, mas jamais privando-o das demais portas.

Desse modo, como forma de compreender mais facilmente a prática de um Sistema Multiportas de Justiça, é possível imaginar um indivíduo que se depara com um conflito e consegue ter à sua disposição vários caminhos para resolvê-lo. Ele poderá buscar diretamente a outra parte, para, sem a interferência de outra pessoa, resolver a questão em conflito. Assim, estará utilizando a porta da Negociação. Ainda, caso infrutífera a primeira tentativa ou desejar de modo imediato, poderá procurar um terceiro, para, dessa forma escolher outros modos de resolução do seu conflito, o qual irá depender da natureza da questão. Poderá desse modo optar pela Mediação, Conciliação ou a própria Justiça Restaurativa. Por fim, caso a pessoa tenha se utilizado de várias formas autocompositivas e não resultar numa resolução ou, se assim desejar, de forma imediata poderá procurar a solução heterocompositiva, na figura do poder Judiciário. Desse modo, Ihe serão possíveis várias formas de resolução, jamais o privando de qualquer uma, mas sim lhe oferecendo todas para que opte por aquela que considere mais adequada, ou aquela que resolver seu conflito em questão.

É nesse sentido que o Projeto de Extensão Conflitos Sociais e Direitos Humanos do Curso de Direito da Unijuí, RS, pode apresentar-se como um meio de aplicabilidade do referido sistema, oferecendo aos assistidos do Núcleo de Prática Jurídica da Universidade Regional várias opções de tratamento de conflitos, mediante a valorização do diálogo entre os envolvidos, a gestão de suas diferenças, o afastamento da violência e da cultura da intolerância e da negação do outro, e sobretudo, apostando na importância da análise e compreensão dos limites e das possibilidades dos envolvidos na apresentação de formas de administração de seus conflitos.

Por fim, o projeto que foi tema central da pesquisa pode ser considerado um modelo de Sistema Multiportas de Justiça, uma vez que traz à prática de Mediação, nas mediações escolares e familiares realizadas no Núcleo de Prática Jurídica, no Campus de Santa Rosa. Oferece, ainda, a prática de Conciliação e em algumas vezes a própria Negociação, nos Balcões do Consumidor, tanto no Campus de Santa Rosa como nos de ljuí e Três Passos, bem como a prática de Justiça Restaurativa, mediante aplicação mais especificamente do Projeto Cidadania para Todos, que em alguns momentos realiza atividades em parceria com o Projeto Conflitos Sociais e Direitos Humanos. Ainda, por meio dos Estágios Supervisionados, oferece ao assistido dos Núcleos de Prática o acesso à Justiça na modalidade de demanda judicial. Assim os assistidos, ao buscarem os Escritórios Modelos da Unijuí (N. P. J.), deparam-se com várias formas de resolução de seus conflitos, observando-se que, 
ao optarem por uma e esta não surtir o efeito desejado, podem buscar pelas outras sem nenhuma limitação, usufruindo de um modelo de Justiça adequado e garantidor de respostas satisfatórias aos conflitos inerentes a vida em sociedade.

\section{REFERÊNCIAS}

A PAZ QUE NASCE DE UMA NOVA JUSTIÇA. Disponível em: http://www1.tjrs.jus.br/export/processos/conciliacao/doc/A_Paz_ que_Nasce_de_uma_Nova_Justica.pdf. Acesso em: 25 jun. 2019.

BOBBIO, Norberto; MATTEUCCI, Nicola; PASQUINO, Gianfranco. Dicionário de Política. 1. ed. Trad. Carmen C. Varriale et al. Coord. trad. João Ferreira. Rev. geral João Ferreira e Luis Guerreiro Pinto Cacais. Brasília: Editora Universidade de Brasília, 1998. 674p. Vol. 1.

CAPPELLETTI, Mauro; GARTH, Bryant. Acesso à justiça. Tradução Ellen Gracie Northfleet. Porto Alegre: Fabris, 1988. 168p.

GABBAY, Daniela Monteiro. Mediação \& Judiciário: condições necessárias para a institucionalização dos meios autocompositivos de solução de conflitos. São Paulo: USP, 2011. 273p. Tese (Doutorado) - Faculdade de Direito da USP, Direito Processual, São Paulo, 2011.

GHISLENI, Ana Carolina. O descrédito na jurisdição e a mediação enquanto política pública eficaz no tratamento dos conflitos conforme a Resolução no 125 do Conselho Nacional de Justiça - CNJ. Santa Cruz do Sul: Essere nel Mondo, 2018.117 p.

GIMENEZ, Charlise Paula Colet. A Justiça Consensual do Tribunal Múltiplas Portas e a Política Pública Norte-Americana de Tratamento de Conflitos: contribuições ao modelo brasileiro. In: Revista Opinião Jurídica, Fortaleza, n. 20, p. 84-111, 2017.

GOLART, Eduarda Aparecida Santos; MAIER, Jackeline Prestes. Justiça restaurativa e violência contra a mulher: uma nova perspectiva de solução eficaz. Disponível em: http://online.unisc.br/acadnet/anais/index.php/snpp/article/view/14687. Acesso em: 25 jun. 2019.

GUERRERO, Luis Fernando. Efetividade das estipulações voltadas à instituição dos meios multiportas de solução de litígios. 2012. 255p. Tese (Doutorado) - USP, Curso de Pós-Graduação da Faculdade de Direito da Universidade de São Paulo - Departamento de Direito Processual - DPC, São Paulo, 2012.

MARZINETTI, Miguel. Justiça multiportas e o paradoxo do acesso à justiça no Brasil: da falência do Poder Judiciário aos métodos integrados de solução de conflitos. Rio de Janeiro: Lumen Juris, 2018. 160p.

MORAIS, José Luis Bolzan de; SPENGLER, Fabiana Marion. Mediação e arbitragem. Alternativas à Jurisdição! 2. ed. rev. e ampl. Porto Alegre: Livraria do Advogado Editora, 2008. 256p.

PAULA, João Antônio de. A extensão universitária: história, conceito e propostas. In: Interfaces - Revista de Extensão da UFMG, Belo Horizonte: v. 1, n. 1, p. 5-23, jul./nov. 2013.

POLÍTICA E DIRETRIZES DE EXTENSÃO DA UNIJUÍ. In: Coleção Cadernos da Gestão Universitária 50. Ijuí: Editora Unijuí, 2013. 52p. PROJETO DE EXTENSÃO CIDADANIA PARA TODOS. Unijuí - Universidade Regional do Noroeste do Estado do Rio Grande do Sul; DCJS - Departamento de Ciências Jurídicas e Sociais. Coordenação: Ester Eliana Hauser; Vigência: 2018/2019. ljuí, 2018.

PROJETO DE EXTENSÃO CONFLITOS SOCIAIS E DIREITOS HUMANOS: Alternativas Adequadas de Tratamento e Resolução. Unijuí - Universidade Regional do Noroeste do Estado do Rio Grande do Sul; DCJS - Departamento de Ciências Jurídicas e Sociais. Coordenação: Fabiana Fachinetto; Vigência: 2018/2019. Ijuí, 2019a.

PROJETO DE EXTENSÃO CONFLITOS SOCIAIS E DIREITOS HUMANOS: Alternativas Adequadas de Tratamento e Resolução. Unijuí - Universidade Regional do Noroeste do Estado do Rio Grande do Sul; DCJS - Departamento de Ciências Jurídicas e Sociais. Coordenação: Fabiana Fachinetto; Vigência: 2015/2018. Ijuí, 2019b.

PROJETO DE EXTENSÃO CONFLITOS SOCIAIS E DIREITOS HUMANOS: Alternativas Adequadas de Tratamento e Resolução. Unijuí - Universidade Regional do Noroeste do Estado do Rio Grande do Sul; DCJS - Departamento de Ciências Jurídicas e Sociais. Coordenação: Fabiana Fachinetto; Vigência: 2014. Ijuí, 2019c.

PROJETO DE EXTENSÃO CONFLITOS SOCIAIS E DIREITOS HUMANOS: ALTERNATIVAS ADEQUADAS DE TRATAMENTO E RESOLUÇÃO. Unijuí - Universidade Regional do Noroeste do Estado do Rio Grande do Sul; DCJS - Departamento de Ciências Jurídicas e Sociais. Coordenação: Fabiana Fachinetto; Vigência: 2013. Ijuí, 2019d.

ROCHA, Leonel Severo. O direito na forma de sociedade globalizada. In: Anuário do Programa de Pós-Graduação em Direito da Unisinos. São Leopoldo: Unisinos, 2001.

SPENGLER, Fabiana Marion. O conflito, o monopólio estatal de seu tratamento e as novas possibilidades: a importância dos remédios ou remédios sem importância? In: SPENGLER, Fabiana Marion; LUCAS, Doglas Cesar (org.). Conflito, jurisdição e direitos humanos: (des)apontamentos sobre um novo cenário social. Ijuí: Editora Unijuí, 2008.

VASCONCELOS, Carlos Eduardo. Mediação de conflitos e práticas restaurativas. 5. ed. rev., atual. e ampl. Rio de Janeiro: Forense; São Paulo: Método, 2017.

ZEHR, Howard. Trocando as lentes: um novo foco sobre o crime e a justiça. Tradução Tônia Van Acker. São Paulo: Palas Athena, 2008. 276p. 